\title{
Multifractal analysis of land use pattern in space and time: A case study in the Loess Plateau of China
}

\author{
De Wang ${ }^{\mathrm{a} b}$, Bojie $\mathrm{Fu}^{\mathrm{a}, *}$, Kangshou Lu ${ }^{\mathrm{c}}$, Luxiang Xiao ${ }^{\mathrm{d}}$, Yuxin Zhang ${ }^{\mathrm{a}}$, Xiaoming Feng ${ }^{\mathrm{a}}$ \\ a State Key Lab. of Urban and Regional Ecology, Research Center for Eco-environmental Sciences, Chinese Academy of Sciences, Shuangqing Road 18, P.O. Box 2871, \\ Beijing 100085, China \\ ${ }^{\mathrm{b}}$ Yantai Institute of Coastal Zone, Chinese Academy of Sciences, P.O. Box 1488, Yantai 264003, China \\ ${ }^{c}$ Department of Geography and Environmental Planning, Towson University, Towson, MD 21252, USA \\ ${ }^{\mathrm{d}}$ College of Geography and Planning, Ludong University, Yantai 264025, China
}

\section{A R T I C L E I N F O}

\section{Article history:}

Received 6 July 2009

Received in revised form 4 December 2009

Accepted 4 December 2009

Available online $\mathrm{xxx}$

\section{Keywords:}

Multifractal

Rényi dimension

Land use pattern

Remote sensing

Scale

\begin{abstract}
A B S T R A C T
Quantifying patterns of great spatial and temporal complexities are a daunting task for landscape ecologists. Multifractals, with which more detailed information can be obtained from a distribution than mono-fractal does, is especially suited to the description of complex patterns. In our paper, three sites $(256 \times 256$ cells per site, $100 \mathrm{~m}$ per cell) from the upper, middle and lower reaches of Yanhe watershed in the Loess Plateau were selected to test the scaling properties of agricultural landscape patterns in 1980, 2000 and 2006 using multifractal Rényi dimensions analysis. We found that: (1) the distributions of cropland, grassland and woodland patterns are multiscaling over nearly four orders of magnitude in scale, whereas water bodies and residential areas are not multifractally distributed, which may result from the resolution of Landsat TM remote sensing images; (2) spatially, the multifractal techniques are capable to uncover subtle differences in land use patterns between different reaches of the watershed that could correspond to their distinct, underlying abiotic and biotic processes; and (3) temporally, the multifractal spectra demonstrate little difference between 1980 and 2000 but a sharp change in 2006, the former depicting the land use patterns in an equilibrium state and the latter the effect of government policies such as large-scale eco-environment conservation programmes starting in the late 20 th century. The fact that scaling behaviors exist across a heterogeneous landscape suggests that there may be some simple mechanism that governs agricultural landscape change. Further work on this problem may improve our understanding of the mechanism and enhance our capability to more effectively manage land use.
\end{abstract}

(C) 2009 Elsevier B.V. All rights reserved.

\section{Introduction}

Selfsimilar patterns exist almost everywhere in ecology, from the organism to the landscape level (Milne, 1991; Scheuring and Riedi, 1994; Gaston and Blackburn, 2000; Li, 2000; Brown et al., 2002; Chen et al., 2005; Makarieva et al., 2005; Zhang et al., 2006; $\mathrm{Wu}$ and $\mathrm{Li}, 2006)$. Such patterns are traditionally characterized by the power law, which is the mathematical relationship that describes any scale-dependent variation. The power law dependence is interpreted as being the result of a fractal distribution with a single fractal dimension. However, mono-fractal analysis techniques may fall short in fully describing landscape patterns (Loehle and Li, 1996), especially for agricultural landscapes, which are mosaics of physical and human-managed patches that vary in size, shape and arrangement (Forman and Gordron, 1986).

\footnotetext{
* Corresponding author. Tel.: +86 10 68597542; fax: +861068597583.

E-mail address: bfu@rcees.ac.cn (B. Fu).
}

In agricultural landscapes, human disturbance is the primary disturbance of natural processes, and results in spatial and temporal changes in land use that lead to increased complexity of land use patterns. However, land use is often constrained by the underlying physical conditions of a landscape (Silbernagel et al., 1997; Verburg and Chen, 2000; Fu et al., 2006). Such physical conditions themselves are often fractally distributed, such as landforms (Mandelbrot, 1983; Gupta and Waymire, 1989) and soil condition (Caniego et al., 2005, 2006; Zeleke and Si, 2006; Ibáñez et al., 2009). Therefore, there is theoretically no single scaling factor describing the scaling of the land use pattern, but rather a spectrum of scaling exponents. In this case the observed pattern should be considered as multifractals (Scheuring and Riedi, 1994; Makarieva et al., 2006), which are associated with nonlinear phenomena and complex systems.

The Chinese Loess Plateau, located in the middle reaches of the Yellow River basin, is the largest region of loess in the world. The area, where agriculture is the principal economic activity, suffers devastating soil erosion. The leading cause of soil erosion in this

1476-945X/\$ - see front matter @ 2009 Elsevier B.V. All rights reserved. doi:10.1016/j.ecocom.2009.12.004 
region is low vegetation coverage as a result of unsuitable land use (Liu, 1999; Fu et al., 2000, 2004). In order to effectively control soil erosion, the Loess Plateau was selected as one of the target areas of the Grain-for-Green Programme, which was a nationwide programme initiated by the central government in 1999. The programme requires all arable lands with a slope greater than $25^{\circ}$ be converted to woodland or pasture, which is more likely to hinder soil erosion than other land use types by reducing detach capacity of rainfall and transport capacity of runoff water. The programme is believed to be one of the world's largest conservation projects (World Wildlife Fund, 2004). However, what the impact the program has on land use patterns and how effective it is remains to be evaluated.

The Yanhe watershed, a semiarid hilly-gullied region within the Loess Plateau of China, was selected as the case study area. The objectives are: (1) to examine if there exists a multifractal scaling law in the agricultural landscape; and (2) to evaluate the applicability of multifractal analysis to characterize agricultural landscape patterns by means of multifractal parameters, namely Rényi dimensions. If such a scaling law does exist, it may help us identify, explain, and control the underlying physical mechanism that governs land use patterns.

\section{Materials and methods}

\subsection{Study area}

Yanhe watershed $\left(108^{\circ} 38^{\prime}-110^{\circ} 29^{\prime} \mathrm{E}, 36^{\circ} 21^{\prime}-37^{\circ} 19^{\prime} \mathrm{N}\right)$ is located in the central part of the Loess Plateau, China (Fig. 1), and covers an area of $7725 \mathrm{~km}^{2}$. The Yanhe River is divided into three reaches (i.e. upper, middle, and lower reaches) by two points, namely Huaziping and Ganguyi (Fig. 1), according to river valley form (Compiling Committee of Yanhe River System, 2000). It has a typical semiarid continental climate with an average temperature of $9{ }^{\circ} \mathrm{C}$ and an average annual precipitation of $520 \mathrm{~mm}$. Annual precipitations are highly variable, with more than $60 \%$ of the rain falling between July and September. Most of the runoff is generally contributed by Hortonian overland flow. The landform is a typical loess hilly-gullied landscape with elevations ranging from $495 \mathrm{~m}$ to $1795 \mathrm{~m}$ above sea level (average $1218 \mathrm{~m}$ ) (Fig. 2). The average slope of the region is $23.5^{\circ}$. The erosion ratio is up to $11,200 \mathrm{t} /$ $\mathrm{km}^{2}$ a. The soils, developed on wind-accumulated loess parent material and characterized by poor vegetation, are fertile but very susceptible to erosion by nature and by intensive human activities. Soil types were divided into five categories according to the Local Soil Classification System for Chinese Loess Plateau (Shaanxi Province Soil Survey Office, 1991): alluvial loess, typical loess, red

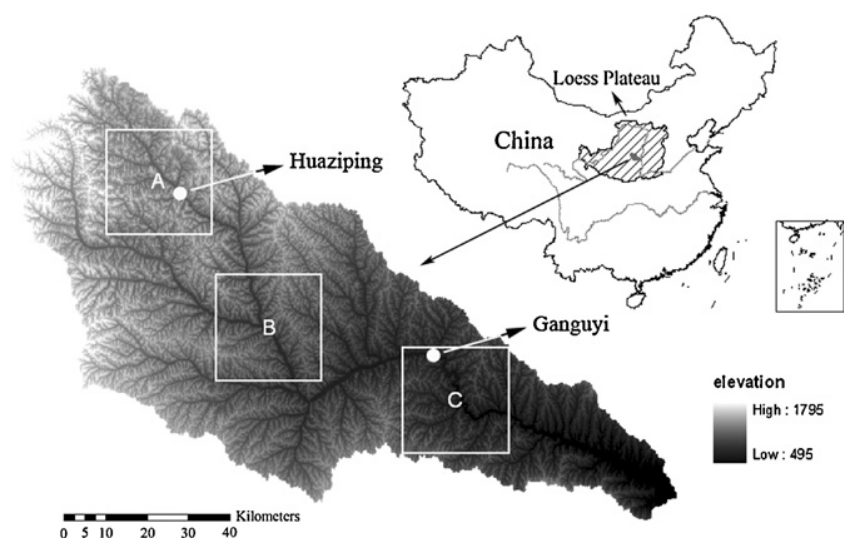

Fig. 1. Study area: A, sample of upper reach of Yanhe River; B, the middle reach and C, lower reach.

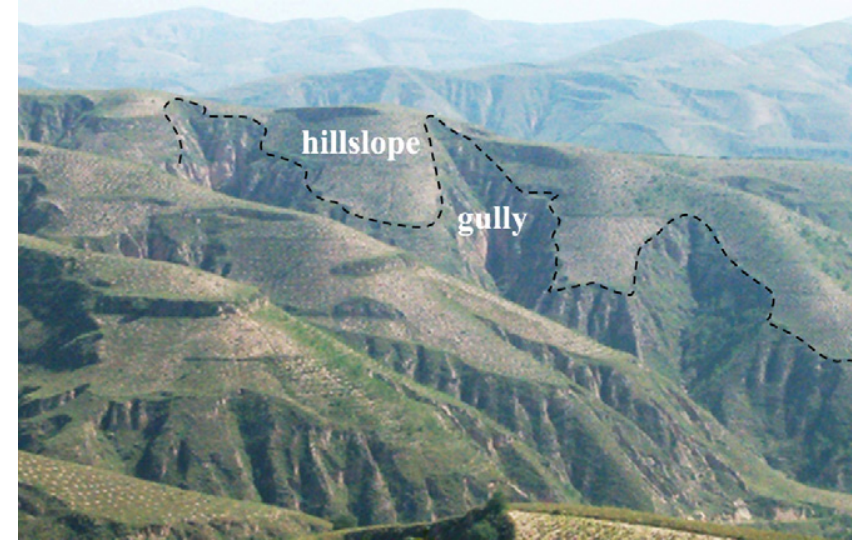

Fig. 2. Hillsope and gully area in the watershed.

loess, eroded loess, and skeletal loess. Sloping cropland and natural grassland with low vegetation coverage were the two dominant landscape types before initiation of Grain-for-Green Programme (Fig. 3).

\subsection{Data used}

Three sets of land use maps (1980, 2000 and 2006, scale $1: 100,000)$, which were derived from remotely sensed Landsat TM images (Zhang, 2002; Feng, 2006), were collected and analyzed (Fig. 3). Maps from 1980 represent land use patterns before initiation of the conservation project (1999), whereas maps from 2000 and 2006 stand for land use patterns after the project has been implemented for 1 year and 7 years respectively. Based on these maps, five land use types were identified: cropland (containing irrigated farmland, terraced farmland, sloping farmland and check-dam farmland), woodland (including orchards, dense woodland, sparse woodland, and shrub land), grassland, water bodies and residential areas.

\subsection{Multifractal analysis}

One of the most popular approaches for multifractal analysis is the conjunction of the moment method with so-called boxcounting algorithm (Borda-de-Água et al., 2002). The method consists of two steps: dividing the object of study (i.e. the land use map) into a set of squares of size $\varepsilon$ and counting the respective area of each component (i.e. different land use types) in each square. Fig. 4 exemplifies the box-counting method for land use map, where Fig. $4 \mathrm{a}$ is the land use map, and Fig. 4b shows the squares with a certain size $\varepsilon$ required to divide the land use map. The same procedure is repeated to create squares with different sizes. $N(\varepsilon)$ is the number of squares with size $\varepsilon=L \times 2^{-k}(k=1,2,3, \ldots, 8)$, where $L$ is the side length of selected land use map. The possibility of different land use types occurring in the $i$ th square of size $\varepsilon$, i.e. $\mu_{i}(\varepsilon)$, is the ratio of area by type/total area of this land use type. Rényi dimension, $D_{q}$, which is called generalized dimension or the method of moments of multifractal analysis, may then be computed for the land use pattern through parameter $q$ by (Rényi, 1970; Hentschel and Procaccia, 1983):

$$
\begin{aligned}
& D_{q} \approx \frac{1}{q-1} \times \frac{\log \left[\sum_{i=1}^{N(\varepsilon)} \mu_{i}(\varepsilon)^{q}\right]}{\log \varepsilon} \quad(q \neq 1) \\
& D_{1} \approx \frac{\sum_{i=1}^{N(\varepsilon)} \mu_{i}(\varepsilon) \log \mu_{i}(\varepsilon)}{\log \varepsilon} \quad(q=1)
\end{aligned}
$$


D. Wang et al./Ecological Complexity $x x x$ (2009) $x x x-x x x$
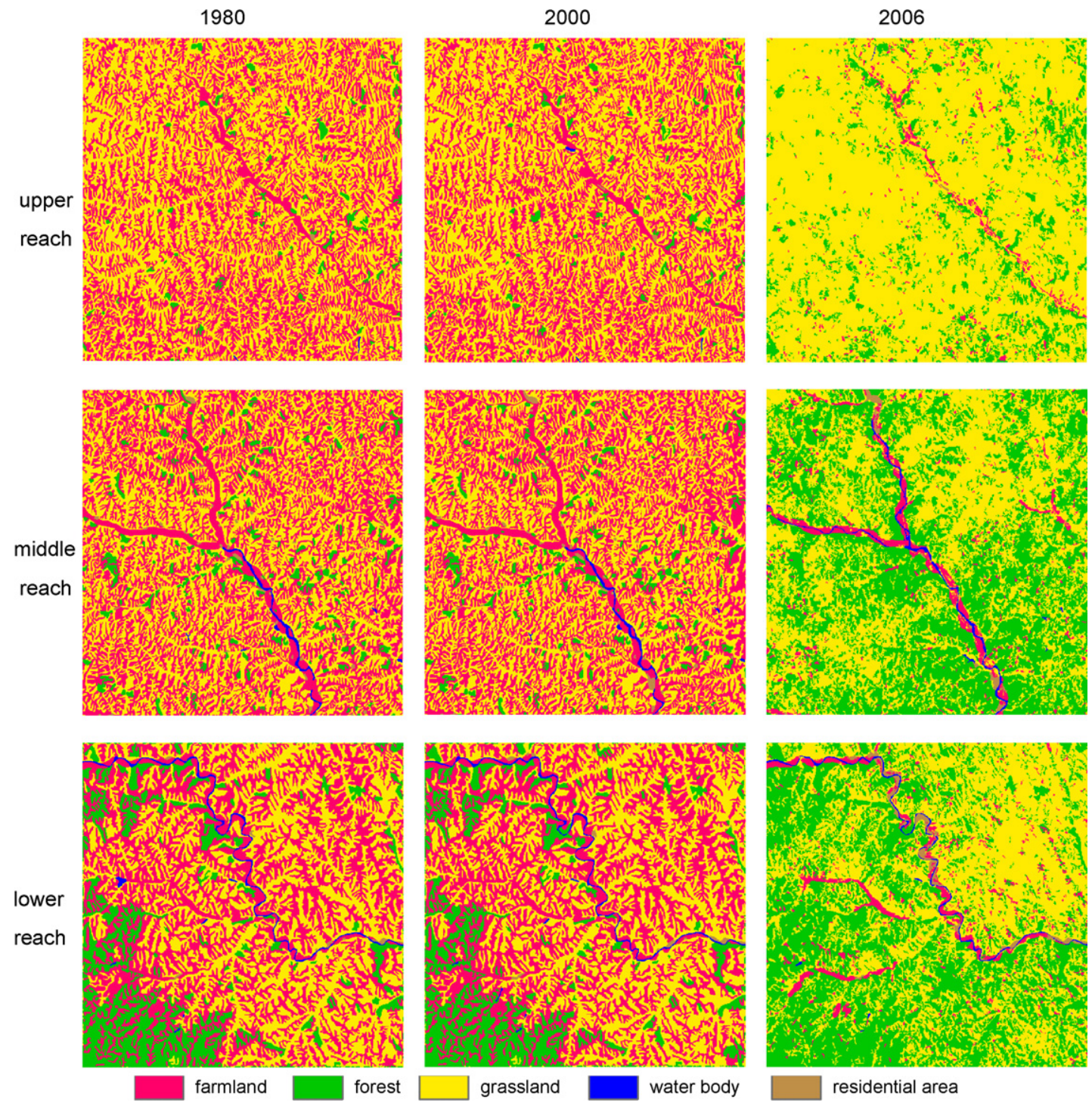

Fig. 3. Land use map of square plot from upper reach, middle reach and lower reach of Yanhe River in years of 1980,2000 and 2006.
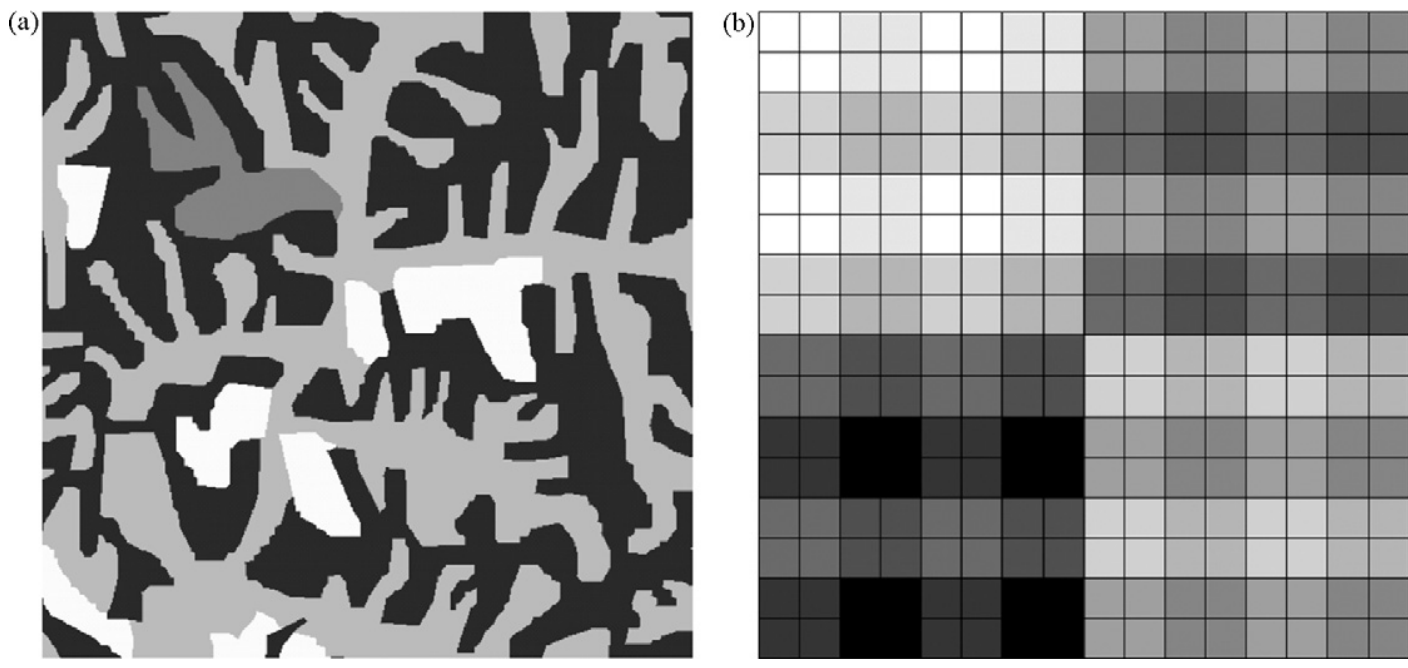

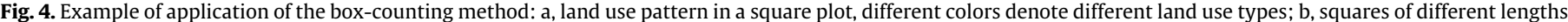

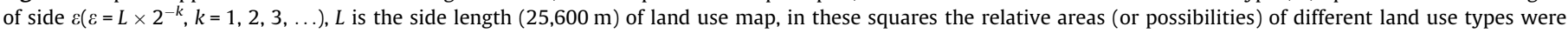
calculated, respectively.

Please cite this article in press as: Wang, D., et al., Multifractal analysis of land use pattern in space and time: A case study ?in the Loess Plateau of China. Ecol. Complex. (2009), doi:10.1016/j.ecocom.2009.12.004 
The Rényi dimension $D_{q}$ is a monotone decreasing function for all real $q$ values within the interval $[-\infty,+\infty]$. Parameter $q$ acts as a scanning tool scrutinizing the denser and rarer regions of the measure $\mu$ (Chhabra and Jensen, 1989; Kravchenko et al., 1999; Montero, 2005). For $q \gg 1$, regions with a high degree of concentration are amplified, while regions with a small degree of concentration are magnified for $q \ll-1$. However, as recognized by many researchers (Feeny, 2000; Borda-de-Água et al., 2002; Lopes and Betrouni, 2009), the empirical density function associated to the $q$-order moment is very noisy at the distribution tails, due to the lack of enough sampling. So the $D_{q}$ values are only reliable for small $q$ (i.e. $q$ tends to zero or $q<0$ ) and not for any value. For $q>0$, the closer $q$ to zero, the more reliable $D_{q}$ values.

The Rényi dimension is known as capacity dimension or boxcounting dimension for $D_{0}$, entropy dimension for $D_{1}$, and the correlation dimension for $D_{2}$. The capacity dimension is also known as the classical fractal dimension and provides the average information for a system. $D_{1}$ is related to information entropy or Shannon entropy (Shannon and Weaver, 1949), and quantifies the degree of disorder present in a distribution. $D_{2}$ is mathematically associated with the correlation function and related to Simpson diversity. When for any value of $q, D_{q}$ are equal, the distribution of points is uniform and then the set is statistically fractal and exact selfsimilar (Parrinello and Vaughan, 2002). More precisely, the set is fractal if $D_{0}$ (the capacity) is a noninteger value, otherwise the distribution is topologically a Euclidean set of points in the $E$ dimensional space.
Considering the areas of each reaches in Yanhe River, the samples have a size of $25,600 \mathrm{~m} \times 25,600 \mathrm{~m}$ from the three reaches (Fig. 1). Considering the image resolution (25 $\mathrm{m}$ after resampling from $30 \mathrm{~m}$ image) and statistical requirement, the minimum squares have a size of $100 \mathrm{~m} \times 100 \mathrm{~m}$. Therefore, the square sizes $\varepsilon=25,600 \mathrm{~m} \times 2^{-k}$ for $k=1,2,3, \ldots, 8$ are $12,800 \mathrm{~m}, 6,400 \mathrm{~m}$, $3,200 \mathrm{~m}, 1,600 \mathrm{~m}, 800 \mathrm{~m}, 400 \mathrm{~m}, 200 \mathrm{~m}$, and $100 \mathrm{~m}$, as exemplified in Figs. 1-3.

\section{Results}

Based on Eqs. (1) and (2), the Rényi dimensions spectra $D_{q}$ of land use patterns are calculated for $-10 \leq q \leq 10$ at 0.5 lag increments, as shown in Fig. 5. $R^{2}$ values are the highest for $q=0$ but decrease in either direction when $q$ becomes higher or lower. Rényi dimensions of the land use patterns for cropland, grassland and forest (except for those in the lower reach) show good linear fits $\left(R^{2}>0.97, p<0.0001\right.$ for $q=0 ; R^{2}>0.76, p<0.01$ for $q=-10$; and $R^{2}>0.92, p<0.001$ for $q=10$ ), whereas those for water bodies and residential areas attain only poor linear fits $\left(R^{2}<0.7, p>0.01\right.$ for $-10 \leq q \leq 10$ ).

Moreover, shapes of the $D_{q}-q$ curves differ among land uses to varying degrees. In general, $D_{q}$ is a non-increasing function of $q$ if the distribution of a land use pattern is multifractal (Peitgen et al., 1992). As shown in Fig. 5, Rényi spectra of cropland, grassland and forest take a generally non-increasing shape in all but the lower reach, indicating that they are almost multifractally distributed (except forest in the lower reach in 1980 and 2000). In contrast, the
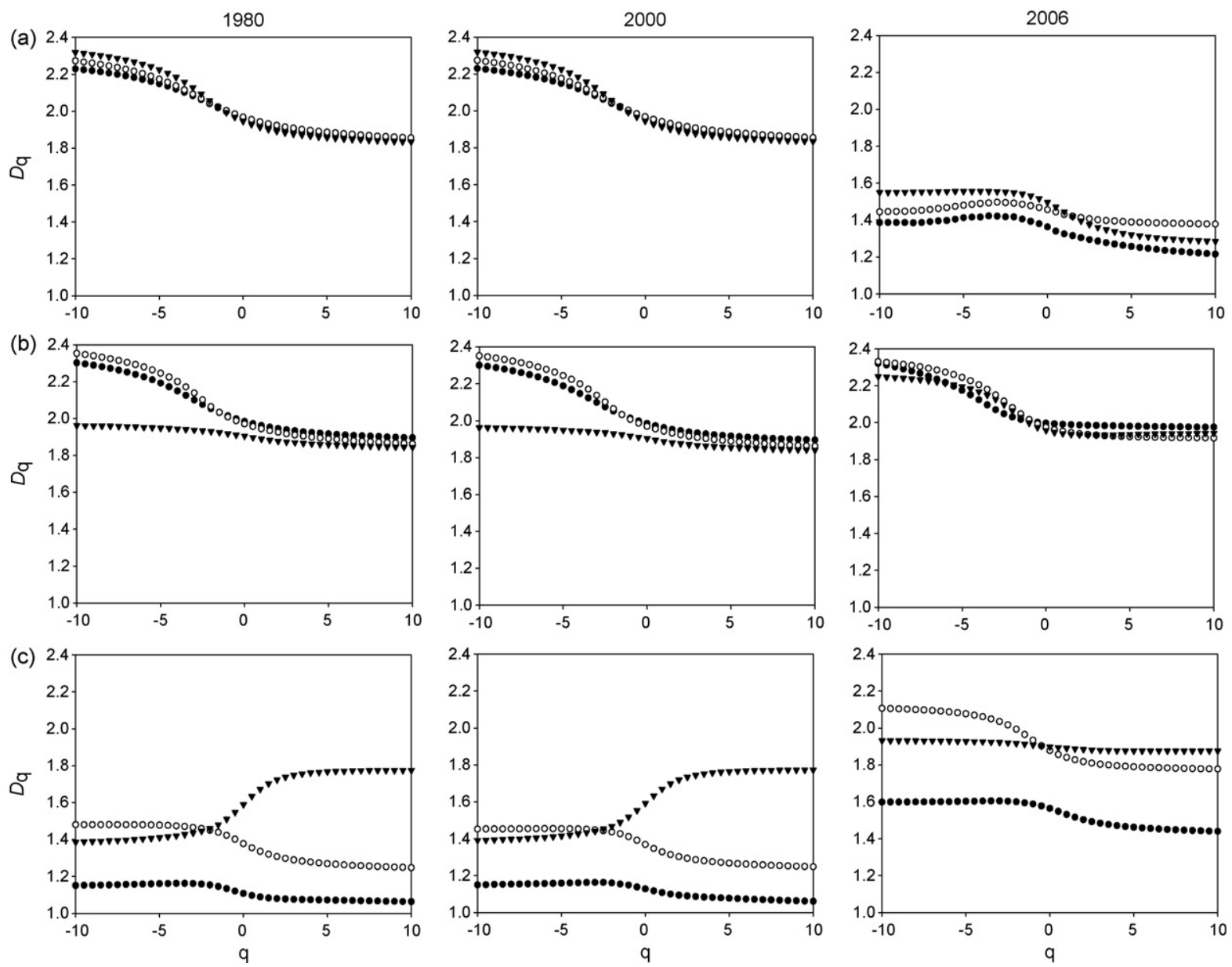

Fig. 5. Spatial differences of Rényi spectra among land use patterns in 1980, 2000, and 2006. $\bigcirc$ upper reach; (c) forest. 
$D_{q}-q$ curves for water bodies and residential areas are unimodal, suggesting that they are not multifractally distributed. Furthermore, the $D_{q}-q$ curves for forest patterns in the lower reach in 1980 and 2000 are monotone increasing, which is not multifractal distribution.

For cropland, grassland and forest, there are some spatial variation in Rényi spectra across the upper, middle and lower reaches of the Yanhe watershed (Fig. 5). For a given year, despite the three Rényi spectra for cropland maintain more similarities in shape across different reaches (Fig. 5a), the spectra show visible difference between different reaches. It was also found that the Rényi spectra for grassland show obvious difference in shape in all cases (Fig. 5b). Moreover, the curves for forest demonstrate more disparities in space (Fig. 5c) than those of cropland and grassland.

The Rényi spectra for years 1980, 2000, and 2006 exemplify the temporal changes of cropland, grassland and forest patterns (Fig. 5). The Rényi spectra demonstrate only slight differences in shape between 1980 and 2000 but sharp changes in both shape and magnitude between 2000 and 2006 when the conservation project had been conducted for 7 years. However, the temporal changes of Rényi spectra vary with land use types and reaches. The Rényi dimensions for cropland decreased by about one-third and those for forest increased in all reaches, though shapes of the curves differ substantially, especially across the reaches.

\section{Discussion}

\subsection{Multifractal characteristics among land use patterns}

As discussed by many researchers (Gupta and Waymire, 1989; Milne, 1991; Tsonis, 1998), in a water-ordering landscape, water erosion may etch the surface in a statistically consistent fashion, leaving ridges and valleys in a fractal pattern. In the hilly-gullied region of the Loess Plateau, the deep loess soils are easily eroded by the highly variable rainfall. As a result, the landscape could be fractal (Rodriguez-Iturbe and Rinaldo, 2001). Operations performed on an existing fractal may generate a set with geometry that is also fractal (Stanley, 1986), such as in the case of topography (Mandelbrot, 1983; Zhang et al., 1999; Martínez et al., 2009).

Many studies have shown that there exists a strong correlation between land use distribution and topography (Rustomji and Prosser, 2001; Silbernagel et al., 1997; Verburg and Chen, 2000; Fu et al., 2006). In the hilly-gullied region of the Loess Plateau, the farm land is often located in the high land, whereas the grassland and woodland often locate in the low land with relative high degree of slope, where it is hard to access for the farming activity (Fig. 2). Therefore, land use distribution may also obey this rule and is fractal or multifractal in a water-ordering landscape such as the hilly-gullied region of the Loess Plateau. Our results show some positive proofs to this point of view. We found that cropland and grassland, having inherited the complexity from the hilly and gullied topography, exhibit a relative high degree of multifractality, particularly where conventional agricultural practice used to prevail and human interventions were intensive. Forest, water body, and residential area are assumed to be multifractal, but their calculated multifractal spectra show little or even no multifractality. The reason may be as follows: (1) for forest, the low multifractality may be attributed to a sampling problem, as in the lower reach plot, the southwester corner is a mountainous area covered by large, concentrated, and contiguous forest patches, which is significantly different from the agriculture landscape of other areas in the watershed (Fig. 3). (2) For water bodies, it is not multifractally distributed. This may not truly represent the reality due to the limitation of the TM images used. For rivers, most of them in this semiarid region are less than $30 \mathrm{~m}$ wide and river networks mainly consist of intermittent and ephemeral streams without water in their channels most of the year except for only a few main courses. Water bodies derived from one-time snapshot TM images certainly underestimate the reality and thus may have misrepresented the distribution patterns of the complex waterordering landscape. (3) For residential areas (mainly cave houses), either remotely sensed orthographic TM images are unable to identify the "underground" cave dwellings or its resolution is too low to recognize such small objects. Actually, residential areas are distributed in the lower hillside along the rivers.

In Figs. 4 and 5, the 2006 cropland spectra of the upper and middle reaches increase for $-10<q<-2$, which is contrary to the theoretical predictions. This may be partially due to classification error inherited from the TM in the source data, partially due to the effect of the conservation project. Converting croplands with a slope greater than $25^{\circ}$ into woodland and grassland also means excluding the lands from the cropland class. In other words, the 2006 croplands are flat with a slope $<25^{\circ}$ and confined within terrace and valleys or floor flood plains of major rivers (Fig. 3). As a result, many cropland patches are smaller than the area of one pixel $(30 \mathrm{~m} \times 30 \mathrm{~m})$. It is possible that if high resolution remote sensing data were available, the trend observed in $D_{q}$ for $-10<q<-2$ would have been reversed.

In landscape research, $D_{0}$ indicates the ability of a pattern to fill the Euclidean space in which it resides. When $D_{0}=2$, all the $2 D$ spaces are occupied. $D_{0}$ values of cropland and grassland are higher than forest in 1980 and 2000, indicating cropland and grassland are widespread with larger area than that of forest. This is in accordance with information obtained from Fig. 3.

\subsection{Multifractal characteristics of land use pattern in space}

In landscapes, the volume of water (i.e. the power that moves material) is low in the upper reaches of the stream and consequently only small rivulets are created. However, power increases downstream as water is accumulated and more concerted cutting of stream banks occur (Milne, 1991). Therefore, river networks in different reaches are at different development stages. This may result in differences in topography that lead to differences in land use patterns. Such differences can be reflected by comparing the shapes of Rényi spectra of land use patterns in different reaches of the watershed (Fig. 5). In the multifractal spectra, information of large patches is amplified when $q \gg 1$, while small patch information is magnified when $q \ll-1$. Thereby we can compare the spectral shapes to acquire the information.

In our case, $D_{q}$ of cropland for $q<0$ in 1980 at the lower reach is higher than those of the upper reach and middle reach (Fig. 5a), then we may infer that there are more small patches of cropland in the lower reach; $D_{q}$ for $q>0$ at upper reach is a little higher than those of middle reach and lower reach, we might infer that there are more large cropland patches in the upper reach. For grassland, $D_{q}$ for $q>0$ at middle reach is a little higher than those of upper reach and lower reach in 1980 and 2000, then we might infer that there are more large grassland patches in the middle reach. For $q<0, D_{q}$ at upper reach in 1980 and 2000 is a little higher than those of middle reach and lower reach, we might infer that there are more small grassland patches in the upper reach. For forest, $D_{q}$ for all $q$ at upper reach is significantly higher than that of middle reach (lower reach forest excluded for non multifractality in 1980 and 2000), then more forest distributed in the upper reach.

This can be explained as follows: in Loess Plateau, gully system expanding and inter-gully area (hillslope) decreasing is the dynamic result of water erosion. Compared with middle and lower reaches, the gully system is relatively young in the upper reach and the hillslope area of the upper reach is larger than that of middle and lower reaches. Then cropland in the upper reaches have relatively larger patches than that of middle and lower 
reaches, because the cropland mainly locates on the hillslope (Fig. 2). Grassland and woodland dominate in middle and lower reaches just because there is more gully area where grassland and woodland often grow.

\subsection{Multifractal characteristics of the land use pattern in time}

In Fig. 5, the multifractal spectra of land use patterns show little difference (almost overlapped) between 1980 and 2000, but display a sharp change in 2006 . This is likely associated with the influence of the nationwide conservation project initiated in 1999. The project required those sloping arable lands with a slope greater than $25^{\circ}$ be converted to woodland or pasture. In 2000 ( 1 year after the project began), the abandoned farmland with planted trees could not be distinguished from cropland in the TM image because the planted trees had little time to grow. However, in 2006 ( 7 years after the project was initiated), the planted trees had grown bigger with larger canopies and show woodland properties in the TM image.

The results of this study indicate that the Rényi spectra of the three land use patterns are not on the same level. Grassland and cropland are dominant patterns over forest pattern in 1980 and 2000. The overlapping of multifractal spectra in 1980 and 2000 indicates that farming activity already reached its maximum and achieved a long-term equilibrium before the conservation project take effect. By 2006, $D_{0}$ of cropland has decreased dramatically from around 2 to around 1.5 (Fig. 5) and grassland and forest had become dominant. $D_{0}$ of forest reach above 1.9. All the three land use (cropland, grassland, and forest) distribution show considerable mulfractality after the conservation project implemented for 7 years (Fig. 5).

It is intriguing that forest patterns at the lower reach in 1980 and 2000 show trends contrary to classical Rényi spectrum, whereas in 2006 the trends reverse and the pattern becomes multifractal. As mentioned previously, the southwestern corner of the lower-reach plot is a mountainous area, which is significantly different from the agriculture landscape of other areas in the watershed. By 2006 or 7 years after the initiation of the conservation programme, the trees planted in the former cropland areas had grown and the forest pattern becomes multifractal. It is reasonable to believe that the forest patterns that evolved as a consequence of the conservation project and the mountainous forest pattern that existed previously is similar to great extent. This may provide useful information as to the effectiveness of conservation project. $D_{q}$ of grassland and forest increase and $D_{q}$ of cropland decrease significantly in 2006 for all reaches in Yanhe watershed, shedding light on the effectiveness of conservation programme.

\section{Conclusion}

In Loess Plateau, water orders landscape undoubtedly, leaving fractal patterns over a large range of scales. Human activities are constrained by the underlying physical condition like topography. So land use pattern may inherit the regularity and complexity from the hilly and gullied topography. Our study supplies positive proof that there exists a multifractal scaling law in the agricultural landscape. The Rényi dimensions are capable of characterizing spatial and temporal differences of different land use patterns. The analysis of multifractal Rényi spectra may provide useful information as to the effectiveness of conservation project.

\section{Acknowledgements}

We thank Prof. Jianguo Wu, Dr. Benjamin Knapp, Mr. Huifeng $\mathrm{Hu}$, and Dr. Virginia Thompson for useful suggestions and English improvement. We thank Prof. Zengxiang Zhang for data support.
This study was financially supported by the National Basic Research Program of China (No. 2009CB421104) and National Natural Science Foundation of China (No. 40930528).

\section{References}

Brown, J.H., Gupta, V.K., Li, B.L., Milne, B.T., Restrepo, C., West, G.B., 2002. The fractal nature of nature: power laws, ecological complexity and biodiversity. Phil. Trans. R. Soc. Lond. B. 357, 619-626.

Borda-de-Água, L., Hubbell, S.P., McAllister, M., 2002. Species-area curves, diversity indices, and species abundance distributions: a multifractal analysis. Am. Nat. 159, 138-155.

Caniego, F.J., Espejo, R., Martín, M.A., José, F.S., 2005. Multifractal scaling of soil spatial variability. Ecol. Model. 182, 291-303.

Caniego, F.J., Ibáñez, J.J., José, F.S., 2006. Selfsimilarity of pedotaxa distributions at the planetary scale: A multifractal approach. Geoderma 134, 306-317.

Chen, X.W., Li, B.L., Collins, S.L., 2005. Multiscale monitoring of a multispecies case study: two grass species at Sevilleta. Plant Ecol. 179, 149-154.

Chhabra, A.B., Jensen, R.V., 1989. Direct determination of the $f(\alpha)$ singularity spectrum. Phys. Rev. Lett. 62, 1327-1330.

Compiling Committee of Yanhe River System, 2000. Yanhe River System. , pp. 75-76 (published in Chinese).

Feng, X.M., 2006. Land use maps in Yanhe watershed in the research center for ecoenvironmental sciences. Chin. Acad. Sci..

Feeny, B., 2000. Fast multifractal analysis by recursive box covering. Int. J. Bifurcation Chaos. 10 (9), 2277-2287.

Forman, R.T., Gordron, M., 1986. Landscape Ecology. Wiley, New York, pp. 620.

Fu, B.J., Chen, L.D., Ma, K.M., Zhou, H.F., Wang, J., 2000. The relationships between land use and soil conditions in the hilly area of the Loess Plateau in northern Shaanxi, China. Catena 39, 69-78.

Fu, B.J., Meng, Q.H., Qiu, Y., Zhao, W.W., Zhang, Q.J., Davidson, D.A., 2004. Effect of land use on soil erosion and nitrogen loss in the hilly area of the Loess Plateau, China. Land Degrad. Dev. 15, 87-96.

Fu, B.J., Zhang, Q.J., Chen, L.D., Zhao, W.W., Gulinck, H., Liu, G.B., Yang, Q.K., Zhu, Y.G. 2006. Temporal change in land use and its relationship to slope degree and soil type in a small catchment on the Loess Plateau of China. Catena 65, 41-48.

Gaston, K.J., Blackburn, T.M., 2000. Global patterns in biodiversity. Nature 405, 220 226.

Gupta, V.K., Waymire, E., 1989. Statistical self-similarity in river networks parameterized by elevation. Water Resour. Res. 25 (3), 463-476.

Hentschel, H.G.E., Procaccia, I., 1983. The infinite number of generalized dimensions of fractals and strange attractors. Physica D. 8, 435-444.

Ibáñez, J.J., Pérez-Gómez, R., San José Martínez, F., 2009. The spatial distribution of soils across Europe: A fractal approach. Ecol. Complex 6 (3), 294-301.

Kravchenko, A., Boast, C.W., Bullock, D.G., 1999. Multifractal analysis of soil spatial variability. Agron. J. 91, 1033-1041.

Li, B.L., 2000. Fractal geometry applications in description and analysis of patch patterns and patch dynamics. Ecol. Model. 132, 33-50.

Liu, G.B., 1999. Soil conservation and sustainable agricultural on the Loess Plateau: challenge and prospective. AMBIO 28 (8), 663-668.

Loehle, C., Li, B.L., 1996. Statistical properties of ecological and geologic fractals. Ecol. Model. 85, 271-284.

Lopes, R., Betrouni, N., 2009. Fractal and multifractal analysis: A review. Med. Image Anal. 13 (4), 634-649.

Makarieva, A.M., Gorshkov, V.G., Li, B.L., 2005. Revising the distributive networks models of West, Brown and Enquist (1997) and Banavar, Maritan and Rinaldo (1999): Metabolic inequity of living tissues provides clues for the observed allometric scaling rules. J. Theor. Biol. 237, 291-301.

Makarieva, A.M., Gorshkov, V.G., Li, B.L., 2006. Distributive network model of Banavar, Damuth, Maritan and Rinaldo (2002): critique and perspective. J. Theor. Biol. 239, 394-397.

Mandelbrot, B., 1983. The Fractal Geometry of Nature. W.H. Freeman and Co., New York.

Martínez, F.S.J., Caniego, J., Guber, A., Pachepsky, Y., Reyes, M., 2009. Multifractal modeling of soil microtopography with multiple transects data. Ecol. Complex 6 (3), 240-245.

Milne, M.T., 1991. Lessons from applying fractal models to landscape patterns. In: Turner, M.G., Gardner, R.H. (Eds.), Quantitative Methods in Landscape Ecology. Springer-Verlag, New York, USA, pp. 199-235.

Montero, E., 2005. Rényi dimensions analysis of soil particle-size distributions. Ecol. Model. 182, 305-315.

Parrinello, T., Vaughan, R.A., 2002. Multifractal analysis and feature extraction in satellite imagery. Int. J. Remote Sens. 23, 1799-1825.

Peitgen, H., Jürgens, H., Saupe, D., 1992. Chaos and Fractals. Springer-Verlag, New York.

Rényi, A., 1970. Probability Theory. Nortn Lolland, Amsterdam.

Rodriguez-Iturbe, I., Rinaldo, A., 2001. Fractal River Basins: Change and Self-organization. Cambridge University Press, Cambridge, pp. 110-120.

Rustomji, P., Prosser, I., 2001. Spatial patterns of sediment delivery to valley floors: sensitivity to sediment transport capacity and hillslope hydrology relations. Hydrol. Process. 15, 1003-1018.

Scheuring, I., Riedi, R.H., 1994. Application of multifractals to the analysis of vegetation pattern. J. Veg. Sci. 5, 489-496.

Shaanxi Province Soil Survey Office, 1991. Shaanxi Province Secondary Soil Survey Data. , pp. 505-510 (published in Chinese). 
Shannon, C.E., Weaver, W., 1949. The Mathematical Theory of Communication. University of Illinois Press, Chicago, IL.

Silbernagel, J., Martin, S.R., Gale, M.R., Chen, J., 1997. Prehistoric, historic, and present settlement patterns related to ecological hierarchy in the eastern upper peninsula of Michigan, U.S.A. Landsc. Ecol. 12, 223-240.

Stanley, H.E., 1986. Form: an introduction to self-similarity and fractal behavior. In: Stanley, H.E., Ostrowski, (Eds.), On Growth and Form: Fractal and Non-Fractal Patterns in Physics. Martinus Nijhoff, Boston, pp. 21-53.

Tsonis, A.A., 1998. Water ordering landscapes. Science 280, 1210-1211.

Verburg, P.H., Chen, Y.Q., 2000. Multiscale characterization of land-use patterns in China. Ecosystems 3, 369-385.

World Wildlife Fund, 2004. Report suggests China's ‘Grain-to-Green’ plan is fundamental to managing water and soil erosion [Internet] 2003 [cited January 8 , 2004]. Available from http://www.wwfchina.org/english/local.php?loca=159.
Wu, J., Li, H., 2006. Perspectives and methods of scaling. In: Wu, J., Jones, K.B., Li, H., Loucks, O.L. (Eds.), Scaling and Uncertainty Analysis in Ecology: Methods and Applications. Springer, Dordrecht, The Netherlands, pp. 1744.

Zeleke, T.B., Si, B.C., 2006. Characterizing scale-dependent spatial relationships between soil properties using multifractal techniques. Geoderma 134, 440452

Zhang, X.Y., Drake, N.A., Wainwright, J., Mulligan, M., 1999. Comparison of slope estimates from low resolution DEMs: scaling issues and a fractal method for their solution. Earth Surf. Proc. Land. 24, 763-779.

Zhang, Y.X., Ma, K.M., Anand, M., Fu, B.J., 2006. Do generalized scaling laws exist for species abundance distribution in mountains? OIKOS 115 (1), 81-88.

Zhang, Z.X., 2002. Land use maps in Yanhe watershed in 1980 and 2000, the institute of remote sensing applications. Chin. Acad. Sci. 